\title{
Polycyclic aromatic hydrocarbons from rural household biomass burning in a typical Chinese village
}

\author{
WANG HaiLin ${ }^{1}$, ZHUANG YaHui ${ }^{1}$, HAO ZhengPing ${ }^{1 \dagger}$, CAO MeiQiu ${ }^{1}$, ZHONG JinXian $^{1}$, WANG XiaoKe ${ }^{1}$ \& \\ NGUYEN Thi Kim Oanh² \\ ${ }^{1}$ Research Center for Eco-Environmental Sciences, Beijing 100085, China; \\ ${ }^{2}$ Environmental Engineering, SERD, Asian Institute of Technology, Pathumthani 12120, Thailand
}

Biomass energy sources are still popular in the rural areas of developing countries for cooking and space heating. Since the incomplete combustion of agricultural residues in home-made ranges might lead to both outdoor and indoor air pollution and cause potential health threat to the rural population, we monitored the ambient levels of 16 US EPA priority polycyclic aromatic hydrocarbons (PAHs) at a typical rural site. Ambient particulate $\mathrm{PAH}$ samples $\left(\mathrm{PM}_{2.5}\right.$ and $\left.\mathrm{PM}_{10}\right)$ were taken during both cooking and non-cooking periods. Source emission monitoring was also conducted for both improved and traditional cooking stoves used in the area. Ambient PAHs had a significant increase during the cooking periods and varied from 72.1 to $554.4 \mathrm{ng} / \mathrm{m}^{3}$. The highest total PAH levels were found during the supper cooking time, in which five- and six-ring species accounted for a large proportion. The observed PAH levels during cooking periods at this rural site were even higher than those in urban areas. A good correlation was found between the benzo[a]pyrene level and the total PAH concentration $(r=0.98)$, making benzo[a]pyrene a potential molecular marker for PAH pollution in the rural areas, where biomass burning is typical. The profiles of the particulate PAHs in both ambient air and source emissions showed a high proportion of high molecular-mass PAHs. In addition, emission factors of 16 PAHs from an improved household stove were found to be significantly lower than those from traditional stoves used in China and in other Asian countries.

biomass burning, rural area, household stoves, PAHs, emission factors, distribution

Traditional biomass combustion for cooking and heating is still popular in the rural areas of China. The straw and stalk output in China reached to about 604 million tons, which is equivalent to 300 million TCE (tons of carbon equivalent). Much of this amount of straw and stalk $(58.7 \%)$ was used for cooking and heating in rural households. A more prudent estimate suggests that consumption of agricultural residues as fuel is about 73 million $\mathrm{TCE}^{[1]}$. Considering the current economic status, biomass fuel will continue to play a significant role in China's rural energy in the future.

Presently, most of the biomass fuel is used at low efficiency in rural areas of developing countries. For example, in domestic cooking stoves, the conversion efficiency is only $10 \%$ to $20 \%$. Consequently, the Chinese government encouraged the dissemination of energysaving kitchen stoves. Dissemination of fuel-saving stoves would save 100 million tons of firewood annually by 2010 , if the stoves actually meet the standard of heat efficiency. However, the heat efficiency of these self-made ranges might not be as high as claimed by CAERDI $^{[2]}$, partly because farmers built most of the brick/clay stoves without meeting the standard parameters recommended by CAERDI. On the other hand, traditional clay/ceramic cook stoves are still available in

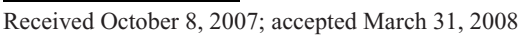
doi: 10.1007/s11430-008-0064-x

†Corresponding author (email: zpinghao@rcees.ac.cn)

Supported by the National Natural Science Foundation of China (Grant No 49392703), the National Science Fund for Distinguished Young Scholars (Grant No. 20725723) and Swedish International Development Agency (AIRPET)
} 
China, especially in southern areas. Generally, these kinds of stoves often result in poor combustion. Emissions from household stoves using biomass fuels could have a concomitant contribution to air pollution and also have adverse health impacts (carcinogens and mutagens in combustion products). High levels of PM, PAHs, and other air pollutants were formed ${ }^{[3]}$, resulting in a series of environmental problems, such as indoor air pollution, local particulate matter pollution, as well as regional and global climate impacts ${ }^{[4-7]}$. PAHs were firstly identified in indoor air during open-pit burning of fuelwood and coal by Mumford et al. ${ }^{[8]}$ Although many papers concerning PAH emissions from automobiles and coal combustion have been published, reports about ambient PAH pollution from biomass combustion are still quite rare. Mandalakis et al. ${ }^{[9]}$ reported that biomass burning contributed about $10 \%-50 \%$ of total PAHs at European background sites. Hargava et al. ${ }^{[10]}$ indicated ambient PAH concentrations increased substantially during cooking hours in rural India and fairly high concentrations of carcinogenic PAHs were emitted during incomplete biomass burning in cooking stoves. Kim et al. ${ }^{[1,12]}$ reported the $\mathrm{PAH}$ emission factors of several kinds of biomass combustion in Thailand and other south Asian countries. Although these studies provide some information on PAH emissions from biomass burning, the PAHs emission levels however may vary substantially, depending on the types of biomass and combustion conditions. Although there are numerous types of improved stoves for biomass fuels in China, scarce studies on $\mathrm{PAH}$ emission factors and PAH ambient levels from biomass combustion have been reported. For better understanding of the PAH pollution problem from biomass burning in China, we monitored the PAHs at a rural site, where the pollutants are expected to be mainly released from local biomass burning sources. In addition, a comparative study on the PAH emission factors and profiles from energy-saving kitchen ranges with those from traditional firewood stoves was also carried out.

\section{Method}

\subsection{Sampling site description}

Sampling PM from biomass combustion emissions was carried out in the village Xuying, located in the southwest part of Nanyang, Henan Province during January and February, 2007. The village was chosen as a PAH monitoring site, because there are no industries but crop fields in that area, and the nearest highway is about 12 kilometers away from the village. Thus, the combustion in the village is expected to be the main PAH source in the air around the village. The major crops are wheat, cotton, corn, and beans. Crop residues are mainly burned in household stoves for cooking and space heating, and only a small fraction of crop residues is used as livestock feed. Besides the crop residues, twigs and leaves of trees are also used as fuel for cooking. Although electricity and coal are also available, they account only for a very small percentage in the local energy sources due to their high commercial prices. The energy consumption in the village Xuying is given in Figure 1. The stoves employed in this rural area are mostly self-made "fuel-saving" stoves. Meanwhile, traditional stoves are also used in this rural area.

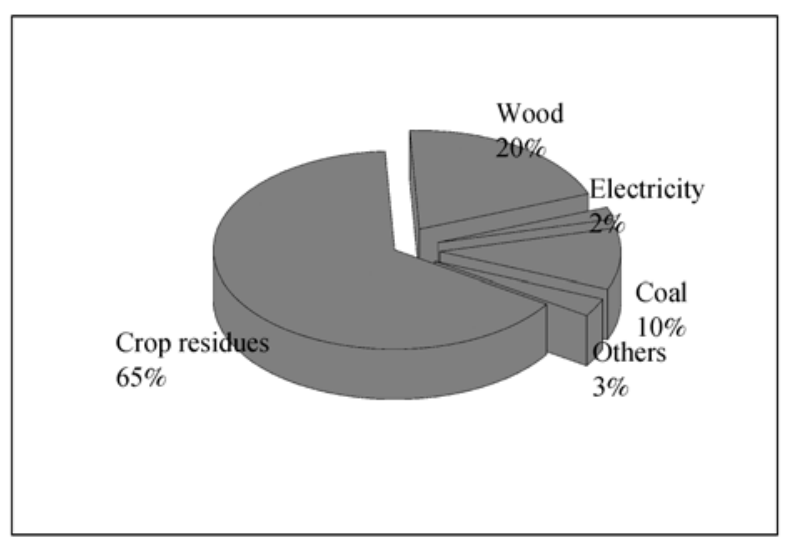

Figure 1 Energy consumption in the village Xuying.

\subsection{Sampling method for ambient particulate PAHs}

Quartz filters (QR100, Advantec, Japan) were used for sampling particulate emissions. The quartz filters were pre-treated by baking at $550^{\circ} \mathrm{C}$ for $12 \mathrm{~h}$ to reduce any residual organic matter on the filters. $\mathrm{PM}_{2.5}$ and $\mathrm{PM}_{10}$ particle samplers (Medium volume, Beijing Dike Inc.) were placed on the roof of a cottage located in the central part of the village. There are 120 households in this village, so the estimated chimneys are 120 on the assumption that each family has one. The inlets of the $\mathrm{PM}_{2.5} / \mathrm{PM}_{10}$ samplers were about $4.5 \mathrm{~m}$ above ground, and hence were about $1-1.2 \mathrm{~m}$ higher than the chimneys of nearby cottages. The $\mathrm{PM}_{2.5}$ and $\mathrm{PM}_{10}$ samplers were calibrated before use and were operated at a constant flow rate of $77.59 \mathrm{~L} / \mathrm{min}$.

Air-borne particulate samples were taken during cooking time and non-cooking time separately. Samples collected during the local cooking periods $(7: 00-9: 00$, 
$12: 00-14: 00$ and 18:00-20:00) were taken as cooking samples, whereas samples taken at other times during a day are classified as non-cooking samples.

\subsection{Sampling method for the determination of PAH emission factors and profile}

Emissions from two cook stoves: improved and traditional, were monitored. For better comparison with parallel studies in other Asian countries under the same umbrella research program, wood was chosen as the test fuel. An improved kitchen stove made of bricks and clay was employed. The size of the stove are: Stoke door $28 \mathrm{~cm} \times 22 \mathrm{~cm}$, chamber $40 \mathrm{~cm} \times 32 \mathrm{~cm}$, pot diameter $40 \mathrm{~cm}$, grate area $47 \mathrm{~cm} \times 32 \mathrm{~cm}^{2}$, chamber volume $40 \mathrm{~cm} \times 32 \mathrm{~cm} \times 47 \mathrm{~cm}$, gap between the pot bottom and the grate $20 \mathrm{~cm}$, cross-sectional area of the flue duct $95 \mathrm{~cm}^{2}$, height of the chimney $1.6 \mathrm{~m}$, cross-sectional area of the chimney $201 \mathrm{~cm}^{2}$. Ten emission samples were collected from this cook stove with two different fuel-stocking methods. The first 5 samples (No. 1-No. $5)$ were taken when fuel-wood was burning on the grate. The heat efficiency of the same stove became lower, when fuel wood was not put on the grate, but on the bottom of the air inlet. The samples No. 6-No. 10 were taken with this mode (without grate). The fuel wood was in the form of sticks $(25-35 \mathrm{~cm}$ long, $1.5-4 \mathrm{~cm}$ wide, $1-2 \mathrm{~cm}$ thick). Batches of $1.5 \mathrm{~kg}$ of this wood were taken for combustion tests. To obtain stable firing, wood sticks were stoked piecewise throughout the sampling period. At the end of each burning cycle, the ash with incompletely burned fuel was collected and weighed. The ash weight was subtracted from the fuel weight.

The samples were taken directly from a sampling port made at the height of $1.2 \mathrm{~m}$ in the vertical chimney of the stove, using a sampling probe nozzle of $6 \mathrm{~mm}$. Throughout the testing period, the flow meter was adjusted to obtain isokinetic sampling. The flue gas was allowed to pass through a quartz filter and then through a semi-volatile sampling train consisting of four impingers. The first impinger was the condensate knockout, while the second one contained distilled water. The third impinger was empty, whereas the fourth one contained the XAD-2 sorbent with the purpose of capturing semi-volatile PAH samples.

For the case of the traditional cook stove, chips of the same fuel wood were also burned. Since the stove does not have a chimney, it was placed in a hood consisting of a chamber and a duct with a sampling system and anemometer. The sampling system consists of a sampling probe, dust collector, thermometer, filter holder, condenser, flask, adsorbent tubes, flow meter, manometer, safety bottle, and vacuum pump. Thus, the flue velocity can be measured by the anemometer and controlled by an adjustable air inlet, and the PAHs in particulate and vapor samples can be sampled. At a constant ventilation rate, the linear velocity of air flowing in the central zone of the duct was in the range of $0.13-$ $0.20 \mathrm{~m} / \mathrm{s}$. The vacuum pump was then adjusted so that the linear velocity in the sampling nozzle was $0.13-$ $0.20 \mathrm{~m} / \mathrm{s}$ to achieve isokinetic sampling. To minimize fluctuation of flow rate of the flue gas in the duct, we added wood sticks into the stove regularly, so that there was a more or less steady flame throughout the combustion and sampling period, and samples No.11-No.15 were taken with this mode

\subsection{Analytical procedure for the determination of PAHs}

16 US EPA Priority PAH standards, namely, naphthalene (NAPH), acenaphthylene (ACY), acenaphthene (ACE), fluorene (FLU), phenanthrene (PHE), anthracene (ANT), fluoranthene (FTH), pyrene (PYR), benzo[a]anthracene $(\mathrm{B} a \mathrm{~A})$, chrysene (CHRY), benzo[b]fluoranthene $(\mathrm{B} b \mathrm{~F})$, benzo $[k]$ fluoranthene $(\mathrm{B} k \mathrm{~F})$, benzo $[a]$ pyrene $(\mathrm{B} a \mathrm{P})$, indeno[1,2,3-cd]pyrene(IcdP), dibenzo[a, $h]$ anthracene $(\mathrm{D} a h \mathrm{~A})$, and benzo[ghi]perylene (BghiP), in a mixture solution of $200 \mu \mathrm{g} / \mathrm{ml}$ were obtained from Accustandard (USA). Neutral silica gel (60-200 mesh) and alumina $(50-200$ mesh) were procured from Qingdao Inc. (China). Sodium sulfate was baked before use at $450^{\circ} \mathrm{C}$. All organic solvents of pesticide analytical grade were purchased from Tedia Co. (USA).

For the ambient air samples, the extraction of one fourth of the filters was done twice with $25 \mathrm{~mL}$ dichloromethane for 30 min using an ultrasonic bath. The total combined filtrate was dried over anhydrous sodium sulfate, and pre-concentrated to $1 \mathrm{~mL}$, solventexchanged to cyclohexane, and then cleaned up in a silica gel column. For elution, $20 \mathrm{~mL}$ cyclohexane and then a mixture of cyclohexane: dichloromethane $=6: 4$ were used. The PAH fraction was finally concentrated to $1 \mathrm{~mL}$.

PAHs were then determined by a GC/MS (Model: Aglient 6890/5973) under the selected ion mode (SIM). 
A HP- 5 capillary column $(30 \mathrm{~m} \times 0.25 \mathrm{~mm} \times 0.25 \mu \mathrm{m})$ was used with helium as the carrier gas controlled at $1.5 \mathrm{~mL} / \mathrm{min}$. One microliter of sample solution exactly spiked with an internal standard of hexamethylbenzene was injected in the splitless mode. The injector and ion source temperatures were kept at 280 and $230^{\circ} \mathrm{C}$, respectively. The GC oven was programmed from $50^{\circ} \mathrm{C} \quad(2$ min) to $300^{\circ} \mathrm{C}$ at $6^{\circ} \mathrm{C} / \mathrm{min}$ and held for $5 \mathrm{~min}$. PAHs in the samples were identified by their retention times and the abundances of selected ions with respect to authentic PAH standards through searching the mass spectral database NIST 02. Calibration curves including 5 different concentrations were constructed using the internal standard method.

For the stove emission samples, the samples (both the particulate and the semi-volatile PAHs) were pretreated according to Kim's method ${ }^{[12]}$. A HPLC (Model: HP1100) with a HP Zorbax SB column $(25 \mathrm{~cm} \times$ $4.6 \mathrm{~mm} \times 5 \mu \mathrm{m}$ ) was employed for the determination of PAHs in PM from wood chip combustion. The working wavelength was $254 \mathrm{~nm}$. Acetonitrile and water was mixed as the mobile phase with a flow rate of $1.5 \mathrm{~mL} / \mathrm{min}$.

\subsection{Quality assurance and quality control}

Analyses of method blanks, spiked blanks, matrix spikes and sample duplicates were done to assure laboratory quality control. GC/MS were tuned daily with decafluorotriphenyphosphine (DFTPP). The instruments were calibrated with PAH calibration standards too. The relative discrepancies between the five-point calibration and the daily calibration values were less than $15 \%$ for all the PAHs analyses. The recoveries based on spiked PAH standard solution for individual PAH ranged from $72 \%$ to $130 \%$.

\section{Results and discussion}

\subsection{Ambient particulate PAH levels in an agricul- tural area}

The total PAH concentrations (sum of the 16 EPA priority pollutants) in PM collected during the cooking periods of this rural area ranged from 72.1 to $554.4 \mathrm{ng} / \mathrm{m}^{3}$ with the mean values of $299.3(\mathrm{SD}=74.7)$ and 372.3 $\mathrm{ng} / \mathrm{m}^{3}(\mathrm{SD}=81.1)$ for $\mathrm{PM}_{2.5}$ and $\mathrm{PM}_{10}$, respectively (Tables 1 and 2). Ratios of PAHs in $\mathrm{PM}_{2.5}$ and in $\mathrm{PM}_{10}$ during the cooking periods were in the range of $65 \%-81 \%$, which were higher than those in the normal time: $46 \%-$ $63 \%$, suggesting that PAHs from biomass burning are mainly associated with air-borne particles of smaller sizes. Total concentrations of 16 PAHs ( $\mathrm{PAHs}$ ) during cooking periods were $4.3-15.8$ times higher than those during non-cooking periods. The highest levels of $\Sigma$ PAHs were found during supper cooking periods, while the lowest levels of $\Sigma$ PAHs were observed during non-cooking time periods (Tables 1 and 2). Generally, the total PAHs levels at the cooking time were higher than those in the non-cooking time (Figure 2). It implies that the PAHs in PM samples could be attributed to biomass combustion activities during the cooking time. The stagnant atmospheric condition brought about build-up of air pollutants, and may contribute to high levels of PAHs in the morning and evening periods. Since supper was more substantial than the breakfast, more biomass fuel was burned for supper preparation. Thus, more pollutants were released during the supper cooking time. The total PAH levels in $\mathrm{PM}_{2.5}$ observed in this rural area approached the levels at an urban traffic site in Beijing, and are much higher than the values in Hong Kong and Houston ${ }^{[13,14]}$.

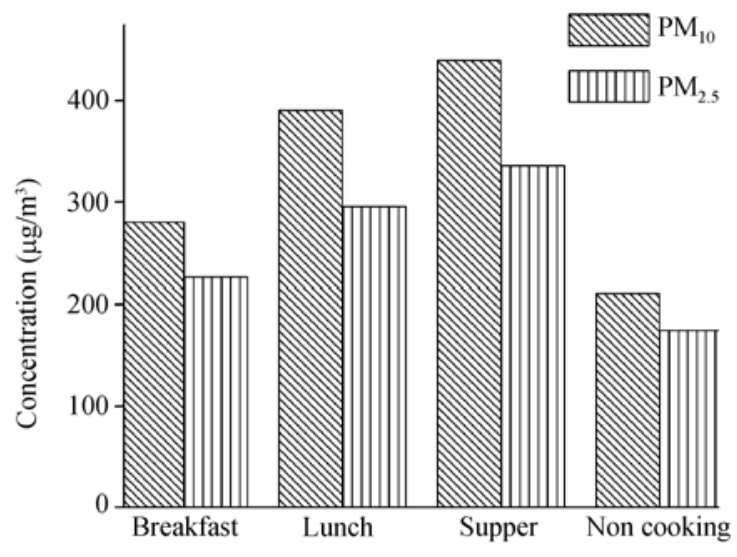

Figure 2 Comparison of total PAHs at different periods.

According to the numbers of aromatic rings, the detected $16 \mathrm{PAH}$ compounds can be divided into three groups, representing 2-/3-ring, 4-ring, and 5-/6-ring PAHs, respectively. Higher proportions of 5- and 6-ring PAH species $(46 \%-70 \%)$ as well as 4 -ring $(25 \%-47 \%)$ species were detected during the cooking periods. The relative abundances of individual PAHs in samples taken in non-cooking and cooking periods were quite similar (Figure 3). As there are no pollution sources other than biomass burning, our results suggest that 
Table 1 Concentrations of individual PAHs in $\mathrm{PM}_{2.5}$ collected at the rural site $\left(\mathrm{ng} / \mathrm{m}^{3}\right)$

\begin{tabular}{|c|c|c|c|c|c|c|c|c|}
\hline \multirow[t]{2}{*}{ PAHs } & \multicolumn{2}{|c|}{$\begin{array}{c}\text { Breakfast cooking } \\
(7: 00-9: 00)\end{array}$} & \multicolumn{2}{|c|}{$\begin{array}{c}\text { Lunch cooking } \\
(12: 00-14: 00)\end{array}$} & \multicolumn{2}{|c|}{$\begin{array}{l}\text { Supper cooking } \\
(18: 00-20: 00)\end{array}$} & \multicolumn{2}{|c|}{ Non-cooking time } \\
\hline & Mean & s.d. & Mean & s.d. & Mean & s.d. & Mean & s.d. \\
\hline NAPH & 3.53 & 1.31 & 4.74 & 2.56 & 2.64 & 0.57 & 1.98 & 0.17 \\
\hline $\mathrm{ACY}$ & 1.77 & 0.52 & 1.69 & 3.07 & 5.61 & 2.19 & 2.33 & 0.66 \\
\hline $\mathrm{ACE}$ & 0.07 & 0.02 & 0.58 & 0.38 & 0.63 & 0.44 & 0.50 & 0.35 \\
\hline FLU & 2.53 & 0.74 & 2.93 & 1.15 & 8.51 & 1.25 & 4.17 & 1.52 \\
\hline PHE & 8.85 & 7.01 & 17.52 & 4.87 & 32.11 & 20.76 & 9.22 & 18.31 \\
\hline ANT & 3.65 & 0.82 & 2.29 & 1.21 & 14.22 & 6.46 & 2.60 & 3.25 \\
\hline FTH & 20.89 & 12.74 & 16.43 & 5.76 & 45.46 & 9.40 & 15.49 & 12.26 \\
\hline PYR & 17.50 & 9.02 & 14.47 & 1.93 & 21.25 & 2.04 & 14.07 & 9.81 \\
\hline $\mathrm{B} a \mathrm{~A}$ & 42.70 & 10.09 & 64.39 & 16.42 & 47.52 & 3.72 & 25.07 & 2.28 \\
\hline CHRY & 5.84 & 1.71 & 12.90 & 8.25 & 12.90 & 1.16 & 10.64 & 5.14 \\
\hline $\mathrm{B} b \mathrm{~F}$ & 7.61 & 0.83 & 8.77 & 5.00 & 17.33 & 1.06 & 5.08 & 4.22 \\
\hline $\mathrm{B} k \mathrm{~F}$ & 9.44 & 1.89 & 22.21 & 1.76 & 25.96 & 2.51 & 11.41 & 6.24 \\
\hline $\mathrm{B} a \mathrm{P}$ & 14.23 & 7.08 & 19.14 & 11.30 & 25.03 & 3.10 & 11.57 & 6.46 \\
\hline $\mathrm{I} c d \mathrm{P}$ & 48.41 & 23.77 & 71.97 & 15.86 & 61.39 & 6.06 & 31.26 & 11.53 \\
\hline $\mathrm{D} a h \mathrm{~A}$ & 21.04 & 0.62 & 8.98 & 1.05 & 24.48 & 6.76 & 12.05 & 1.20 \\
\hline $\mathrm{BghiP}$ & 17.63 & 7.97 & 27.99 & 4.37 & 30.07 & 3.89 & 15.39 & 9.39 \\
\hline
\end{tabular}

Table 2 Concentrations of individual PAHs in $\mathrm{PM}_{10}$ collected at the rural site $\left(\mathrm{ng} / \mathrm{m}^{3}\right)$

\begin{tabular}{|c|c|c|c|c|c|c|c|c|}
\hline \multirow[t]{2}{*}{ PAHs } & \multicolumn{2}{|c|}{$\begin{array}{c}\text { Breakfast cooking } \\
7: 00-9: 00\end{array}$} & \multicolumn{2}{|c|}{$\begin{array}{c}\text { Lunch cooking } \\
\text { 12:00-14:00 }\end{array}$} & \multicolumn{2}{|c|}{$\begin{array}{c}\text { Supper cooking } \\
18: 00-20: 00\end{array}$} & \multicolumn{2}{|c|}{ Non-cooking time } \\
\hline & Mean & s.d. & Mean & s.d. & Mean & s.d. & Mean & s.d. \\
\hline NAPH & 3.12 & 1.60 & 2.97 & 1.08 & 4.89 & 3.34 & 1.30 & 0.36 \\
\hline $\mathrm{ACY}$ & 4.25 & 1.21 & 3.13 & 0.86 & 6.15 & 1.56 & 3.12 & 1.27 \\
\hline $\mathrm{ACE}$ & 0.24 & 0.05 & 0.79 & 0.23 & 0.86 & 0.50 & 0.57 & 0.18 \\
\hline FLU & 7.25 & 4.17 & 5.32 & 2.17 & 4.39 & 4.50 & 4.12 & 0.14 \\
\hline PHE & 10.12 & 2.90 & 11.24 & 6.31 & 21.45 & 13.69 & 11.58 & 6.04 \\
\hline ANT & 5.44 & 2.25 & 4.41 & 0.23 & 8.18 & 9.86 & 7.93 & 2.53 \\
\hline FTH & 28.12 & 2.50 & 19.71 & 2.29 & 40.08 & 27.62 & 23.35 & 8.44 \\
\hline PYR & 25.14 & 4.29 & 17.75 & 1.16 & 38.06 & 24.76 & 19.79 & 5.87 \\
\hline $\mathrm{B} a \mathrm{~A}$ & 29.89 & 10.49 & 59.86 & 9.69 & 66.60 & 10.60 & 19.94 & 9.03 \\
\hline CHRY & 18.19 & 2.46 & 35.75 & 10.58 & 23.20 & 11.38 & 9.62 & 7.22 \\
\hline $\mathrm{B} b \mathrm{~F}$ & 13.31 & 4.11 & 21.82 & 5.29 & 16.75 & 7.32 & 13.25 & 0.83 \\
\hline $\mathrm{B} k \mathrm{~F}$ & 23.01 & 2.00 & 34.35 & 2.73 & 28.35 & 8.01 & 17.73 & 5.06 \\
\hline $\mathrm{B} a \mathrm{P}$ & 21.02 & 3.80 & 32.17 & 6.71 & 25.68 & 4.95 & 16.72 & 3.38 \\
\hline $\mathrm{I} c d \mathrm{P}$ & 53.06 & 19.39 & 80.14 & 31.35 & 74.22 & 37.16 & 27.80 & 12.24 \\
\hline $\mathrm{D} a h \mathrm{~A}$ & 16.20 & 9.21 & 12.70 & 4.33 & 47.71 & 9.68 & 13.52 & 4.04 \\
\hline $\mathrm{B} g h i \mathrm{P}$ & 25.25 & 6.57 & 48.48 & 6.84 & 36.11 & 8.99 & 20.30 & 7.74 \\
\hline
\end{tabular}

PAHs in this rural area came essentially from one identified source-biomass burning and are indicative of a pyrolytic origin.

Among all the 16 PAHs, indeno[1,2,3-cd]pyrene was the most predominant species and accounts approximately for $20 \%$ and $17 \%$ of the total PAHs in $\mathrm{PM}_{2.5}$ and $\mathrm{PM}_{10}$, respectively. In addition, the carcinogens ( $\mathrm{B} a \mathrm{~A}$, CHRY, B $b F, \mathrm{~B} k \mathrm{~F}, \mathrm{~B} a \mathrm{P}$, and $\mathrm{D} a h \mathrm{~A})$ and co-carcinogens (FLU, PYR, and BghiP) were prevalent in most samples. $\mathrm{B} a \mathrm{P}$, a 5-ring polycyclic aromatic hydrocarbon with mutagenic and highly carcinogenic properties, was de- tected in the range of $1.5-32.7 \mathrm{ng} / \mathrm{m}^{3}$. Its daily average concentrations were 17.72 and $23.9 \mathrm{ng} / \mathrm{m}^{3}$ in this rural area in $\mathrm{PM}_{2.5}$ and $\mathrm{PM}_{10}$, respectively, which already exceeded the guideline value of $1 \mathrm{ng} / \mathrm{m}^{3}$ recommended by WHO, and were higher than the levels in Hong Kong and some cities in US and Italy ${ }^{[13-15]}$. Furthermore, BaP can be taken as a marker for combustion-derived $\mathrm{PAHs}^{[16]}$, since its concentration in petroleum is usually negligibly low. Our finding of a significant correlation between $\mathrm{B} a \mathrm{P}$ and ( $\Sigma 16 \mathrm{PAHs}-\mathrm{B} a \mathrm{P})(r=0.98, p<0.0001)$ confirms the view of a general pyrolytic origin of PAHs 


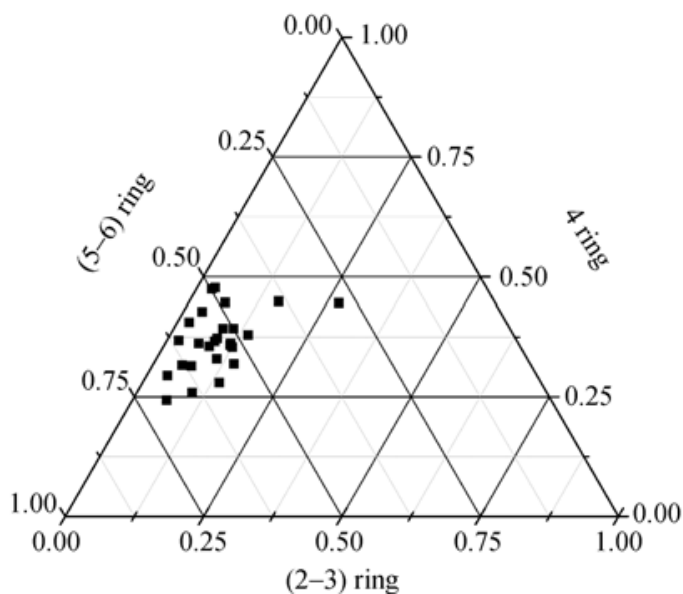

Figure 3 Triangular diagram of percentage concentrations of the 16 PAHs during the cooking and non cooking time.

in $\mathrm{PM}$ at this rural sampling site. The ratios of PHE/ANT, CHRY/B $a$ A, FLU/PYR in this study were $<10,<1$, and $<1$, respectively. According to Baumard et al. ${ }^{[17]}$ and Soclo et al. ${ }^{[18]}$, such values, as we found in this study, can be considered as a proof of their pyrolytic origin.

\subsection{Emission factors of PAHs from the improved and traditional stoves}

The emission factors for improved stoves (both the types of improved stoves with a grate and without a grate) were lower than those determined for a traditional cook stove without flue. The sum of PAH emission factors for improved stoves with a grate and without a grate account for $32 \%$ and $14 \%$ of the sum of PAH emission factors for the traditional stoves, respectively. This implies that the improved stoves could reduce PAH emissions. As compared with results in earlier studies ${ }^{[11,12]}$, our emission factors are about $50 \%$ lower.

The emission factors (Table 3) of 16 PAHs on a wood-weight basis $(\mathrm{mg} / \mathrm{kg})$ were in the range of $5-56$ $\mathrm{mg} / \mathrm{kg}$ for all three types of combustion conditions, whereas a similar study in Thailand on emissions of the same 16 PAHs gave a value of $108 \mathrm{mg} / \mathrm{kg}$ for wood stoves $^{[12]}$. The emission factors of carcinogens $(\mathrm{B} a \mathrm{~A}$, CHRY, $\mathrm{B} b \mathrm{~F}, \mathrm{~B} k \mathrm{~F}, \mathrm{~B} a \mathrm{P}$, and $\mathrm{D} a h \mathrm{~A}$ ) from all three types of stoves in our case were found to be in the range of 1.6 $-45 \mathrm{mg} / \mathrm{kg}$, whereas $\mathrm{Kim}$ et al. ${ }^{[12]}$ reported $14 \mathrm{mg} / \mathrm{kg}$ for the carcinogens. According to the survey made by Smith et al. ${ }^{[19]}$, a range of $47-250 \mathrm{mg} / \mathrm{kg}$ was given for wood stoves and $6-200 \mathrm{mg} / \mathrm{kg}$ was given for fireplaces on these PAHs. Thus, our results with Chinese stoves fall in the lower range of emission factors from wood burning in Asian domestic stoves.

\subsection{Comparison of the distribution of PAHs in am- bient and source samples}

According to Soclo et al. ${ }^{[18]}$, the ratio of LMW/HMW (namely, the sum of the low molecular-weight PAH concentrations/the sum of the high molecular-weight PAH concentrations) can be used to differentiate PAHs of pyrogenic and petrogenic origins, which is based on the fact that the PAHs of a petrogenic origin consist predominantly of lower molecular-weight PAHs (three to four rings), whereas the PAHs from a pyrogenic

Table 3 PAH emission factors from wood combustion in stoves $(\mathrm{mg} / \mathrm{kg})^{\text {a) }}$

\begin{tabular}{|c|c|c|c|c|c|c|c|c|c|}
\hline \multirow{2}{*}{ PAHs } & \multicolumn{3}{|c|}{ Samples $1-5$} & \multicolumn{3}{|c|}{ Samples 6-10 } & \multicolumn{3}{|c|}{ Samples $11-15$} \\
\hline & Meas & Calc & s.d. & Meas & Calc & s.d. & Meas & Calc & s.d \\
\hline NAPH & 3.92 & - & 2.16 & 1.03 & - & 0.57 & 4.71 & - & 1.84 \\
\hline $\mathrm{ACY}$ & n.d. & n.d. & & n.d. & n.d. & & n.d. & n.d. & \\
\hline ACE & 2.76 & - & 2.46 & 1.67 & - & 0.98 & 0.9 & - & 0.8 \\
\hline FLU & 0.67 & - & 0.22 & 0.3 & - & 0.38 & 2.18 & - & 2.95 \\
\hline PHE & 0.39 & 0.02 & 0.25 & 0.5 & 0.02 & 0.41 & 0.98 & 0.04 & 1.12 \\
\hline ANT & 0.24 & 0.01 & 0.1 & 0.17 & 0.01 & 0.16 & 0.45 & 0.02 & 0.77 \\
\hline FTH & 0.39 & 0.05 & 0.23 & 0.35 & 0.04 & 0.26 & 1.04 & 0.13 & 1.00 \\
\hline PYR & 0.54 & 0.11 & 0.25 & 0.39 & 0.08 & 0.31 & 1.52 & 0.3 & 1.00 \\
\hline $\mathrm{B} a \mathrm{~A}$ & 0.07 & 0.02 & 0.06 & 0.03 & 0.01 & 0.04 & 2.35 & 0.77 & 2.19 \\
\hline CHRY & 0.25 & 0.13 & 0.24 & 0.06 & 0.03 & 0.06 & 0.35 & 0.18 & 0.36 \\
\hline $\mathrm{B} b \mathrm{~F}$ & 0.12 & 0.07 & 0.13 & 0.45 & 0.26 & 0.86 & 0.58 & 0.34 & 0.47 \\
\hline $\mathrm{B} k \mathrm{~F}$ & 0.23 & 0.11 & 0.16 & 0.12 & 0.06 & 0.1 & 0.95 & 0.46 & 1.24 \\
\hline $\mathrm{B} a \mathrm{P}$ & 0.34 & 0.19 & 0.34 & 0.04 & 0.02 & 0.05 & 0.8 & 0.46 & 0.61 \\
\hline $\mathrm{I} c d \mathrm{P}$ & 0.33 & 0.25 & 0.34 & 0.06 & 0.05 & 0.13 & 0.28 & 0.21 & 0.26 \\
\hline $\mathrm{D} a h \mathrm{~A}$ & 0.65 & 0.65 & 0.51 & 0.12 & 0.12 & 0.24 & 0.5 & 0.5 & 0.39 \\
\hline BghiP & 1.31 & 1.31 & 1.66 & 0.03 & 0.03 & 0.04 & 21.09 & 21.09 & 20.56 \\
\hline
\end{tabular}

a) Meas, measured amount in particulate and vapor phases; Calc, calculated amount in the particulate phase with exclusion of the amount in the vapor phase, using Kim's ratios; s.d., the standard deviations. 
source generally have higher molecular weights. However, in this study, the LMW/HMW ratios of samples taken from stove flue gas were relatively high (1.25 averagely), and the results seem to be contrary to the Soclo's criterion mentioned above: in our samples taken from the stove flue gas, the concentrations of NAPH, ACE, FLU, PHE and ANT, which belong to the low molecular-weight PAHs (LMW), are relatively high as compared with the high molecular-weight PAHs (HMW), such as FLU, PYR, B $a \mathrm{~A}, \mathrm{CHRY}, \mathrm{B} b \mathrm{~F}, \mathrm{~B} k \mathrm{~F}, \mathrm{~B} a \mathrm{P}, \mathrm{I} c d \mathrm{P}$, $\mathrm{D} a h \mathrm{~A}$, and $\mathrm{B} g h i \mathrm{P}$. On the other hand, in our samples collected from ambient air during the cooking period the 5- and 6-ring PAHs were predominant (Figure 3). This controversy can be explained by the fact that PAHs in both the particulate phase and vapor phase were collected and measured in our emission factor study, whereas only PAHs in the particulate phase were collected and measured in our ambient air samples. The PAHs in vapor phase evidently are of lower molecular weights, therefore a direct comparison of the ambient PAH profile with the emission PAH profile is not feasible. For a rational comparison with ambient samples, we
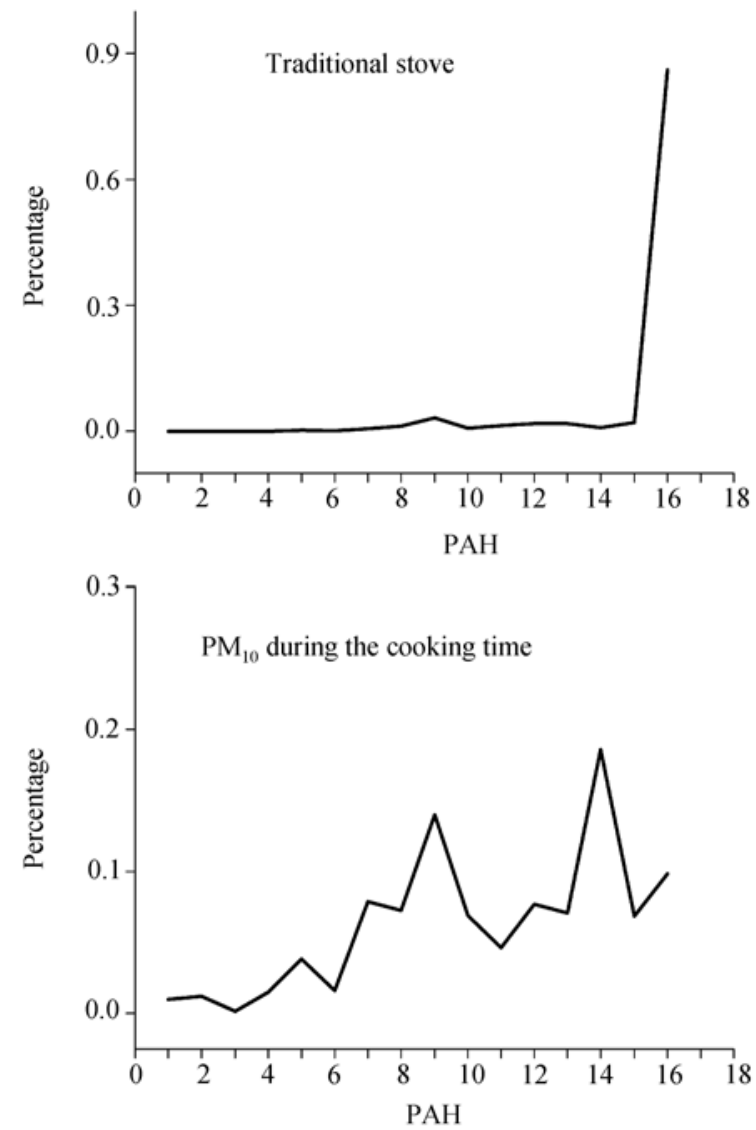

should exclude the PAHs in the vapor phase in our stove flue gas samples and take into account only the PAHs in the particulate phase in stove flue gas (see columns "Calc" in Table 3). Here we used the ratios of individual PAHs in the vapor and particulate phases given by Kim et al. ${ }^{[11]}$.

We can see that the distributions of individual PAH in ambient air and in the stove emissions from wood combustion are different (Figure 4). PAHs in $\mathrm{PM}_{2.5}$ and $\mathrm{PM}_{10}$ taken during the cooking period have similar distribution. $\mathrm{B} a \mathrm{~A}$ and $\mathrm{I} c d \mathrm{P}$ comprised of higher proportions, whereas low molecular weight PAHs have only a moderate percentage. Regarding the PAHs from source emissions, their characteristic is a relatively high proportion of BghiP, while the proportions of low molecular weight PAHs are negligible. BghiP comprised of $86 \%$ and $45 \%$ of the total PAHs from wood combustion in a traditional stove and in an improved stove (with a grate), respectively. Consequently, we could conclude that poor combustion condition may lead to a higher proportion of high molecular weight components of PAHs. Both in ambient air and source emission samples, we found that
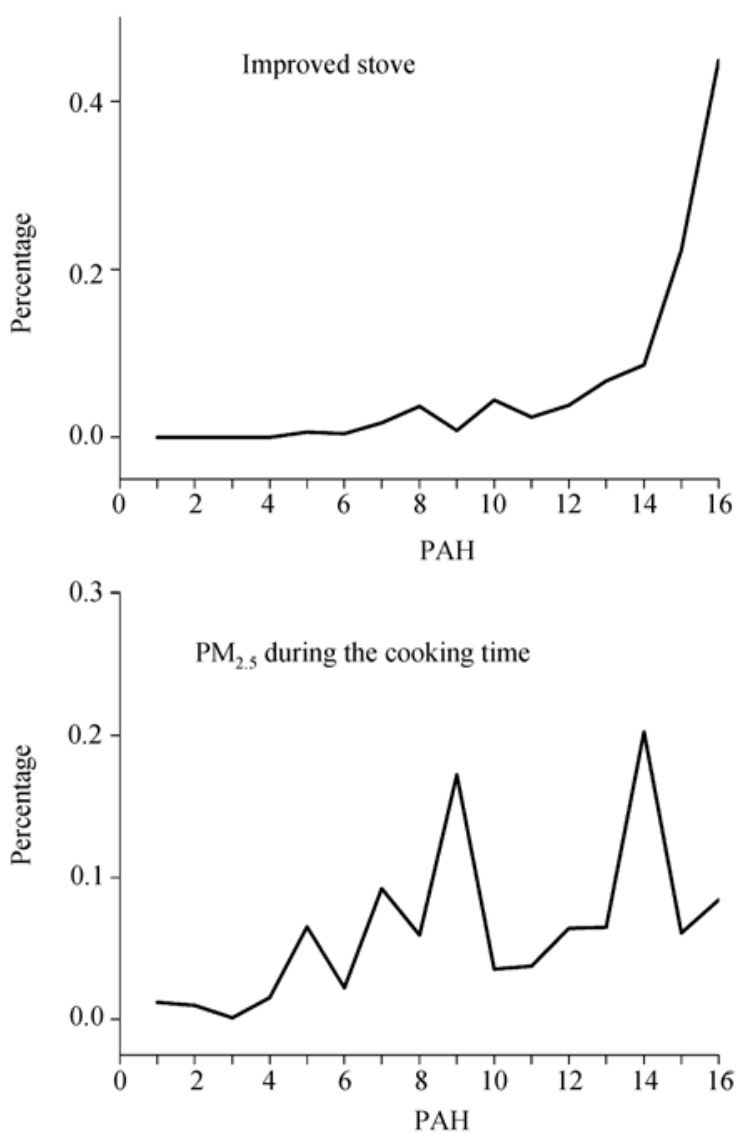

Figure 4 The percentages of individual PAHs during the cooking periods and in emission factor tests. 1- NAPH; 2-ACY; 3-ACE; 4-FLU; 5- PHE; 6-ANT; 7-FTH; 8-PYR; 9-B $a \mathrm{~A} ; 10-\mathrm{CHRY}$; 11-B $b F$; 12-BkF; 13-B $a \mathrm{P} ; 14-\mathrm{I} c d \mathrm{P} ; 15-\mathrm{D} a h \mathrm{~A} ; 16-\mathrm{B} a h i \mathrm{P}$. 
proportions of individual PAHs are in the same order, i.e., HMW > MMW (the sum of the medium molecular-weight PAH concentrations $>$ LMW. It implies that biomass burning produces more PAHs of high molecular weights.

\section{Conclusions}

The ambient levels of 16 PAHs in air-borne particulate in the village Xuying during the cooking time ranged from 72.1 to $554.4 \mathrm{ng} / \mathrm{m}^{3}$, with mean values of $(299.3 \pm$ 74.7) and $(372.3 \pm 81.1) \mathrm{ng} / \mathrm{m}^{3}$ for $\mathrm{PM}_{2.5}$ and $\mathrm{PM}_{10}$, respectively. Compared with the non-cooking periods, PAHs have an increase of $74 \%$ and $77 \%$ for the $\mathrm{PM}_{2.5}$ and $\mathrm{PM}_{10}$, respectively. The high levels of PAHs during the cooking periods in this rural area are comparable with the levels in urban areas worldwide, showing a relatively significant $\mathrm{PAH}$ pollution. The highest levels of PAHs were found during the supper cooking time, indicating more biomass were combusted for supper. Five- and six-ring PAHs were predominant at this rural

1 MOA/DOE (Ministry of Agriculture, China/Department of Energy, U.S.A.). Project Expert Team Assessment of Biomass Resource Availability in China. Beijing: China Environmental Science Press, 1998

2 Chinese Agricultural Engineering Designing Institute \& Beijing Agricultural Engineering University. Agricultural Engineering Handbook. Beijing: Agricultural Press, 1993. 47

3 Zhuang Y H, Cao M Q, Wang X K, et al. Spatial distribution of trace gas emissions from burning crop residue in China. In: Levine J S, ed. Biomass Burning and Global Change. Cambridge: MIT Press, 1996. $764-770$

4 Bruce N, Neufeld L, Boy E, et al. Indoor biofuel air pollution and respiratory health: the role of confounding factors among women in highland Guatemala. Int J Epidem, 1998, 27(3): 454-458

5 Thompson A M, Witte J C, Hudson R D, et al. Tropical tropospheric ozone and biomass burning. Science, 2001, 291(5511): 2128-2132

6 Jacobson M Z. Strong radioactive heating due to the mixing state of black carbon in atmospheric aerosols. Nature, 2001, 409(6821): 695-697

7 Guo H, Wang T, Simpson I J, et al. Source contributions to ambient VOCs and CO at a rural site in Eastern China. Atmos Environ, 2004, 38(27): $4551-4560$

8 Mumford J L, Helmes C T, Lee X M, et al. Mouse skin tumorigenicity studies of indoor coal and wood combustion emissions from homes of residents in Xuan Wei, China with high lung cancer mortality. Carcinogenesis, 1990, 11: 397-403

9 Mandalakis M, Gustafsson O, Alsberg T, et al. Contribution of biomass burning to atmospheric policyclic aromatic hydrocarbons at three European background sites. Environ Sci Technol, 2005, 39(9): $2976-2982$

10 Hargava A, Khanna R N, Bhargava S K, et al. Exposure risk to car- site, obviously supporting their pyrogenic origin. Since most of the carcinogenic PAHs were detected, PAH pollution from biomass burning in rural areas should not be overlooked.

PAH emission factors from rural household stoves with wood chips as fuel were determined, ranging from 5 to $56 \mathrm{mg} / \mathrm{kg}$, with mean values of $12.2 \pm 9.1,5.3 \pm 4.5$ and $36.0 \pm 35.6 \mathrm{mg} / \mathrm{kg}$ for improved stoves with grates, improved stoves without grates, and traditional stoves, respectively. The lower emission factors for the improved stoves indicate that improved combustion conditions could significantly reduce PAH emissions. And a comparison of $\mathrm{PAH}$ distribution in ambient air and in source emissions suggests that biomass burning may lead to the formation of high molecular-weight PAHs.

The authors gratefully appreciate the support from the AIT/SAREC Asian Regional Research Program for Energy, Environment and Climate Program. Deep appreciation is also extended to Profs. B. Bhattacharaya and L. Reutergard for their interest and support to biomass combustion studies in Asian countries.

cinogenic PAHs in indoor-air during biomass combustion whilst cooking in rural India. Atmos Environ, 2004, 38(28): 4761-4767

11 Kim O N T, Albina D O, Ping L, et al. Emission of particulate mater and polycyclic aromatic hydrocarbons from select cookstove-fuel systems in Asia. Biomass Bioenergy, 2005, 28(6): 579-590

12 Kim O N T, Reutergardh L B, Dung N T. Emission of polycyclic aromatic hydrocarbons and particulate matter from domestic combustion of selected fuels. Environ Sci Technol, 1999, 33(16): $2703-2709$

13 Guo H, Lee S, Ho K F, et al. Particle-associated polycyclic aromatic hydrocarbons in urban air of Hong Kong. Atmos Environ, 2003, 37(38): 5307-5317

14 Fraser M P, Yue Z W, Tropp R J, et al. Molecular composition of organic fine particulate matter in Houston, TX. Atmos Environ, 2002 36(38): $5751-5758$

15 Caricchia A M, Chiavarini S, Pezza M. Polycyclic aromatic hydrocarbons in the urban atmospheric particulate matter in the city of Naples (Italy). Atmos Environ, 1999, 33(23): 3731-3738

16 Magi E, Bianco R, Lanni C, et al. Distribution of polylcyclic aromatic hydrocarbons in the sediments of the Adriatic sea. Envrion Pollut, 2002, 119(1): 91-98

17 Baumard P, Budzinski H, Garrigues P, et al. Polylcyclic aromatic hydrocarbons in recent sediment and mussels (mytilus edulis) from the western Baltic Sea: Occurrence, bioavailability and seasonal variations. Mar Environ Res, 1999, 47(1): 17-47

18 Soclo H H, Garrigues P H, Ewald M. Origin of polylcyclic aromatic hydrocarbons (PAHs) in coastal marine sediments: case studies in Cotonou (Benin) and Aquitaine (France) areas. Mar Pollut Bull, 1999, 40(5): $387-396$

19 Smith K R, Aggarwal A L, Dave R M. Air Pollution and Rural Biomass Fuels in Developing Countries: A Pilot Village Study in India and Implications for Research and Policy. Atmos Environ, 1983, 17(11): $2343-2362$ 